\title{
The Oceans and Climate
}

BOOK BY GRANT BIGG

REVIEW BY LLOYD D. KEIGWIN

273 pages, Cambridge University Press, 2003, ISBN 0-521-81570-3, hardback, \$100, ISBN 0-521-01634-7, paperback, $\$ 50$

It is difficult to imagine a natural system more complicated than the climate system. With its extraterrestrial forcing, as well as various terrestrial components in the atmosphere, the cryosphere, the biosphere, the solid Earth, the ocean, and countless feedbacks among them, the climate system almost defies description. Who among us could master all those subjects? Understanding, mitigating, and preparing for climate change is one of the great challenges facing humanity this century, but how can we present all the issues and uncertainties to the general public? One approach is to write an authoritative text directed at students at the undergraduate level.

Such a book is now available in its second edition: The Oceans and Climate, by Grant Bigg. Although this text focuses on ocean-atmosphere interactions, it begins with a thorough overview of radiation budgets, oceans and currents, the solid Earth, the time scales of climate change, and modeling. The following chapters are then organized according to the coupling of constituents within the climate system.

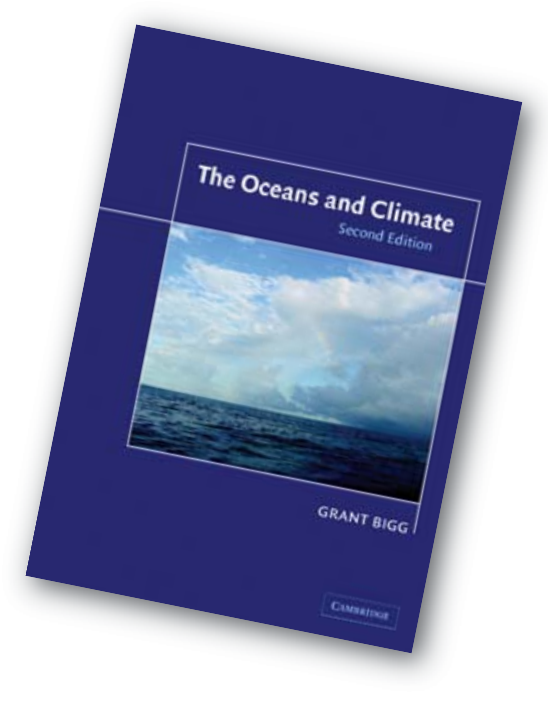

The second chapter, on ocean-atmosphere physical interaction, is all about the exchange of energy and momentum. It begins with a discussion of radiation, moisture, heat exchange, momentum transfer, and the principles governing temperature, salinity, and density in the ocean. Next, the author describes the balance of forces in the climate system including geostrophy, Coriolis, and tides. This naturally leads to waves, and particle exchange. Coverage of ocean circulation begins with Ekman transport and moves from there to wind-driven and thermohaline circulation. Finally, there is a focus on how the ocean affects atmospheric circulation through the influence of hurricanes and mesocyclones. Each chapter ends with recommendations for further reading, usually to other texts. To keep the text manageable, primary literature is not cited, and only rarely does the author refer to a particular individual. An example in the second chapter is the recognition that Arnold Gordon first described the ocean "conveyor," although he has not been its most vocal proponent. The captions contain proper citations for the excellent figures that generally come from journal articles, and a full reference list is found in the back of the book.

Chapters 3 and 4 cover chemical and biogeochemical interactions, respectively. In the former, the discussion focuses on the ocean-atmosphere boundary layer, with emphasis on gas exchange, the carbon cycle, particle exchange, and tracers such as radiocarbon. The latter chapter ranges from phytoplankton growth to compounds other than $\mathrm{CO}_{2}$, including those based on N, S, and I, and their cycles. While methane is noted as a greenhouse gas, the author might also have noted the strong evidence for climate forcing by methane in the geological past.

The fifth chapter looks at large-scale

Lloyd D. Keigwin (Ikeigwin@whoi.edu) is Senior Scientist, Woods Hole Oceanographic Institution. 
interactions between the atmosphere and ocean. This topic includes the consequences of the longitudinal asymmetry of tropospheric pressure systems, and the relationship between atmospheric pressure systems and oceanic distribution of sea surface temperatures. These considerations account for the distribution of maritime climates, patterns of rainfall and drought, and for cyclogenesis. Twenty pages are devoted to discussion of $\mathrm{El}$ Niño/Southern Oscillation phenomena, but in a map of the global impacts of El Niño (Figure 5.37), the Atlantic Ocean is missing! Finally, in this chapter, the concept of abrupt change in thermohaline circulation is introduced. This is new to the current edition, which was completed in summer 2002. Modeling and paleoceanographic evidence for the role of freshwater in interrupting convective overturn are featured, but it would have been worth showing that the Nordic seas have been freshening continually for the past 40 years as pointed out by Dickson and others in spring 2002 (Nature, 416:832).

Chapters 6 and 7 deal with the history and the future of climate change. Chapter 6 begins by examining the warm world of the Cretaceous, followed by progressive Tertiary glaciation and the recent ice ages. The end of the last glacial period is described in some detail, as is the climate of the past 10,000 years. For the most part, these sections are upto-date-a notable achievement for the author in a fast-changing field. The last part of this chapter presents evidence for $20^{\text {th }}$ Century change in climate, in- cluding the history of El Niño events and the North Atlantic Oscillation. The final chapter deals with the thorny problems of distinguishing natural from anthropogenic climate change in recent decades, and predicting the future. It builds on all of the previous chapters and gives a very balanced treatment of these problems. I particularly enjoyed the section on feedbacks, which illustrates all the uncertainties in what will happen next.

In summary, I agreed to review this book because I needed a refresher course, and I am very pleased with the result. Grant Bigg clearly discusses a staggering diversity of topics and weaves them together in a coherent manner. With everything related to everything else, it is easy to imagine getting bogged down, but the chapters and sections are divided logically and cross-referenced where appropriate. The Oceans and Climate would be an excellent starting point for a course for advanced undergraduates, but it could also be distilled down to the fundamentals of climate change for non-science majors. I recommend it highly for either application. 伲

\section{Books Received for Review}

- Changing Sea Levels: Effects of Tides, Weather and Climate

by David Pugh

Cambridge University Press, 258 pp.

- Surf Science: An Introduction to Waves for Surfing

by Tony Butt and Paul Russell with Rick Grigg

University of Hawaii Press, 142 pp.

\section{Upcoming Events}

\section{Environmental Modeling for} North American Coastal Waters: Impact Assessment, Resource Management and Mitigation

October 19-21, 2004

Washington, DC USA

www.sintef.no/imems2004

\section{Ocean Optics XVII}

October 25-29, 2004

Fremantle, Australia

www.oceanopticsconference.org

American Meteorological Society 85th Annual Meeting \& Exhibition January 9-13, 2005

San Diego, CA USA www.ametsoc.org/meet/85annual 